coveries, thereby giving the Royal Institution an impetus it has never lost. Successive generations have estimated this shining character in different ways. Here now is not only a new book about Davy, but a new kind of book about him. Sir Harold Hartley has been opening new windows on the history of chemistry ever since his study of Mitscherlich more than half a century ago. Now, after a lifetime of research and administration, he writes of Davy the scientist as no one has quite done before, expressing the relation of Davy's work to the rest of the chemistry of his time.

Other biographies have recited the events of his life, or illuminated the romantic character of his personality and its effect on the appreciation of science by the educated public of Regency London, or praised his experimental genius without qualification. Hartley includes only the essential chronology of events, and gives only enough space to Davy's philosophy and poetry to keep the reflective man in balance with the investigator. The chemistry is the thing and Hartley manages very well that most difficult of the historian's tasks: to keep before the reader's mind the problems as they were seen at the time.

The discovery of new elements was Davy's most obvious achievement, but he was not as poor a theorist as is often said, and Hartley claims that his break with Lavoisier's oxygen theory of acids was a great, and Davy's greatest, contribution to chemistry. Berzelius had to point out that Davy lacked a systematic training so that he failed to promote progress as consistently as he might have done; nevertheless, he could speak of him, on his death, as the greatest chemist of his time.

Hartley's excellent book endorses this opinion, with learning and affection.

Frank Greenaway

\section{FRENCH MODELS}

\section{Éléments de Logique Mathématique}

Théorie des Modèles. By G. Kreisel et J. L. Krivine. (Monographies de la Société Mathématique de France Nr. 3.) Pp. viii +212. (Paris: Dunod, 1967.) 58 franes. This little book derives from a course of lectures given by the senior author in the University of Paris; it is an account of some elementary results in the theory of models with indications of applications which the theory has in other branches of mathematics.

Model theory is a study of the relationship of formal systems to mathematical structures (the so-called models) which satisfy them. In place of the notion of formal inference model theory introduces the concept of consequence, a conclusion $A$ being a consequence of a set of formulae $A$ if every model which satisfies all the formula $A$ also satisfies $A$. The principal result of the theory of models is that a consequence $A$ of a set of formulae $A$ (in first order predicate logic) is a consequence of a finite subset of $A$. This result may be applied to show, for instance, that in a first order calculus with equality, addition and multiplication and constants 0,1 , a formula which is satisfied in every commutative field of characteristic zero is also satisfied in every commutative field of sufficiently great characteristic.

To facilitate a comparison of the models of a system the notion of one model being rigidly contained in another is introduced, and a model $M$ (not necessarily a model of $A$ ) is said to be rigidly contained in the class of models of a set $A$ if $M$ is rigidly contained in every model of $A$. It is shown that the field of rational numbors is rigidly contained in every commutative field of characteristic zero, but that the field of complex rational numbers is not rigidly contained (though contained) in every algebraically closed commutative field of characteristic zero.

R. L. Goodstein

\section{WHAT SCIENCE IS LIKE}

The Art of the Soluble

By P. B. Medawar. Pp. 160. (London: Methuen and Co., Ltd., 1967.) 25s. net.

THIs collection of essays (not to mention one presidential address to the British Association) is in every way a proof that Sir Peter Medawar is one of that small company whose writings lose nothing, and may even gain, by being reprinted. For in this way it is easier to distinguish the consistent thread in what Medawar is saying about the character of science from the particulars of the circumstances which have prompted the separate pieces. It is also easier to enjoy the way he writes when there are pages and pages to wallow in.

Defence against the heterodox takes up a good deal of space in the Art of the Soluble, and it is all good constructive stuff, and entertaining as well. Medawar's review of Teilhard de Chardin's The Phenomenon of Man, published in Mind in 1961, has of course done much to call that particular spade a spade. One of his literary tricks is to give his knives an occasional extra twist under the guise of indulgence or even something pretty close to affection, and it is in this spirit that he writes in his preface: "A good deal of Teilhard is nonsense, but on further reflection $\mathrm{I}$ see it as a dotty euphoristic kind of nonsense, very greatly preferable to solemn long-faced germanic nonsense. There is no real harm in it".

Those whom Medawar attacks should plainly fear most of all the chance that he may soften, and half forgive them. And yet he can write with great affection for Herbert Spencer, do much to make the memory of Spencer's love-hate relationship with Darwinism respectable gives Spencer's attempt to describe a great evolving system for the whole universe the credit of being a "great adventure" whose failure stands honourable comparison with the ways in which the combined forces of modern exponents of information theory, probability and thermodynamics have failed to produce a "theory of Order". Perhaps the only jarring note is that Medawar himself, like Spencer, may be asking for too much.

John Maddox

\section{ROAD WORK}

The Theory of Road Traffic Flow

By Winifred D. Ashton. (Methuen Monographs on Applied Probability and Statistics.) Pp. viii +178 , (London: Methuen and Co., Ltd.; New York: John Wiley and Sons, Ltd., 1966.) 30s. net.

DEVELOPMENTS in probability theory and in mathematical modelling of complex processes have caused a revolution in the management of situations where crowds interact with conflict or congestion, but where the individuals must retain some freedom of choice. The new analytical tools, collectively called "operations research" or "systems engineering", were partly invented and brilliantly applied to telephone traffic by A. K. Erlang, beginning about 1905. Only in the past fifteen years have they been used effectively in the description and control of automobile traffic. While the theory is still fragmentary, there are already many situations where intuition and simple tabulation of past behaviour can be replaced by systematic and accurate analysis.

Although a previous book by F. Haight in 1963 reviewod some topics, Miss Ashton offers the first fairly comprehensive text aimed at readers without knowledge of the original literature. Her basic presentation for flow on roads without intersections includes methods for measuring traffic stream parameters; the fundamental relation between flow magnitude and vehicle concentration, and models ranging from "follow-the-leader" differential equations to a compressible fluid analogy. A 